\title{
SOBRE LAS FORMAS DE ESCLEROSIS MULTIPLE DE CURSO EXTREMADAMENTE BENIGNO Y PROLONGADO
}

\author{
UUIS BARRAQUER-BORDAS*
}

\begin{abstract}
RESUMEN - El autor presenta la historia clínica de tres pacientes afectos de un cuadro clínico de esclerosis múltiple de evolución muy prolongada y de sintomatología típica aunque leve. En los tres casos una RNM confirmó el diagnóstico clínico. En el paciente con una evolución más larga, los primeros síntomas se esbozaron en 1943, cuando tenía 19 años, practicándose la primera exploración clínica en 1945. Este enfermo ha sido controlado por última vez en enero de 1996. Este mismo mes fueron revisados asimismo los otros dos pacientes. Como conclusión, el autor subraya la necesidad de tener muy en cuenta la realidad de casos de esclerosis múltiple de evolución "muy benigna".
\end{abstract}

PALABRAS-LLAVE: esclerosis múltiple, formas extremamente benignas, evolucion prolongada.

\section{Multiple sclerosis: on extremely mild forms with very long evolution}

ABSTRACT - The author presents the clinical history of three patients with a clinical picture of multiple sclerosis with a very long evolution and with a typical but mild symptomatology. In each case the diagnosis was corroborated by a MR imagenery. In the patient with a longer evolution the first symptoms, very smooth, appeared in 1943, when he was 19 years old, and the first clinical exploration was performed in 1945 . We made the last control of this man in January, 1996. The other two patients were also controlled this same month. In conclusion, the author stressed the need of having always in mind the possibility of a "very benign" form of evolution of multiple sclerosis.

KEY WORDS: multiple sclerosis, extremely mild forms, very long evolution.

La esclerosis múltiple (EM) o en placas o diseminada es una afección "seria" del sistema nervioso central (SNC), que ha sido presentada muchas veces - de forma explícita o implícita como de peor pronóstico del que realmente puede tener, ya que en este aspecto unos y otros enfermos difieren muy mucho entre sí. El Cardenal Yves Congar, de brillante y heroica memoria, ha fallecido con esta afección a la edad de 90 años.

Aunque se fundó, p.ej., en España la “Asociación de enfermos y familiares" (AEDEM), con el ánimo de difundir el conocimiento y los métodos de estudio de esta afección - su epidemiología, p.ej. - así como la informacíon sobre sus posibilidades terapéuticas, suele insistirse demasiado, sobre todo por parte de los "medios de comunicación" - incluso en las mismas películas dedicadas a los problemas que ella plantea en la presentación y recuerdo de las variantes evolutivas graves y aún trágicas, lo que necesariamente comporta un sesgo viciado, que puede inducir - y que de hecho conduce - a que muchos de los pacientes a los que se anuncia que sufren una EM, sospechen de inmediato con vehemencia que el curso de su proceso va a ser "terrible". Bien es verdad, que cabe entonces el reconfortante consuelo del ejemplo ofrecido por el poeta y amigo Miguel Martí i Pol, que, aún vejada su arquitectura física por graves limitaciones - "amb vidres a la sang" - como traducen bellamente fragmentos de sus poemas que acompañan al Prólogo que compuse para el

*Consultor-Director emérito, Servicio de Neurología (Escuela de Neurología-1882), Hospital de la Sta. Creu i St. Pau, Barcelona, Catalunya, España. Aceite: 8-fevereiro-1997. 
libro sobre la EM que propició la AEDEM, ha sabido mantener activa y tersa su labor y verbo poético, de forma admirable, rica y generosa.

El presente artículo - bastante atípico desde algunos puntos de vista - tiene el carácter de una cierta confidencia, exponiendo el curso que me atrevo a calificar de "extremadamente benigno" de tres enfermos afectos EM, seguidos alrededor de medio siglo, todos ellos con una clínica y unas neuroimágenes en la RNM plenamente convincentes, los cuales aún en la actualidad pueden llevar una vida normal o prácticamente normal. Trátase, de hecho, de variantes extremas en el seno de las bien conocidas "formas benignas" de la EM. Por lo demás, cabe recordar aquí, aunque sea de paso, que existen aportaciones, de Europa y de los EEUU, de necropsias que han mostrado lesiones típicas de EM correspondientes a pacientes que no habían consultado jamás por síntomas propios de tal afección. Quico, Leocadia y Emilia sí que han sufrido limitaciones, más o menos apreciadas y apreciables, inducidas por su enfermedad desmielinizante, pero han luchado con bravura ante ellas, han llegado al año 1996 con 40 e aún más de 50 años de enfermedad a cuestas y han estabelecido conmigo una amistad que me honra.

\section{CASOS}

Caso 1. Quico, nacido en 1924, acude por primera vez a nuestra consulta privada el 14 de noviembre de 1945, siendo estudiado por L. Barraquer Ferré y por mí. Narra que desde hace dos años nota inseguridad en la marcha, debilidad motora generalizada de grado moderado, más notoria en extremidades inferiores y diplopía ocasional según sea la posición en que tenga la cabeza. Su marcha aparece como vacilante y al cerrar los ojos se hace imposible. Se constata una hiperreflexia rotuliana y aquílea, con clonus de rótula y un signo de Babisnki bilateral. Hay un nistagmus en la mirada hacia ambos lados, más acusado cuando se dirige a derecha. Diplopia. Reflejos cutáneos abdominales abolidos en el lado derecho. Resto de la exploración normal. No sufre ni ha sufrido vértigos ni dificultades esfinterianas. Tampoco temblor de acción.

Insistiendo en la anamnesis, el cuadro parece haberse iniciado insidiosamente. Así, p. ej., ya en 1943, al querer cruzar un riachuelo saltando de piedra en piedra, le fallaba con frecuencia la exactitud del salto y se mojaba muchas veces los pies; asimismo, al chutar una pelota se caía fácilmente. En vista de todo ello, ya el 7 de marzo de 1950, en una nueva visita, formulamos la presunción de que se trataría de una "forma de evolución lenta", desde luego, de EM.

En tal ocasión se constató una paraparesia espasmódico-atáxica, aumentado la ataxia al cerrar los ojos, lo que se correspondía con un Romberg positivo, aunque no sistematizado. La sensibilidad vibratoria, no obstante, estaba conservada. Diadococinesia aceptablemente mantenida. No dismetría, pero sí lentitud, en la prueba dedo-nariz. Diplopía que aumenta con la mirada lateral, con nistagmus de segundo grado. Refiere sensaciones vertiginosas en los cambios de posición de la cabeza.

El diagnóstico clínico fue compartido, poco después, por el Dr. R. Sales Vazquez. Unos años más tarde, pedimos unas radios de cráneo para excluir una impresión basilar.

Hemos seguido el enfermo, aunque muy de tarde en tarde, constatándose la persistencia de un síndrome vestibular central, de un síndrome piramidal con Babinksi bilateral (que ocasionalmente no fué franco, p. ej. en octubre de 1966) y, por todo lo dicho, de su neta, aunque moderada, inseguridad en la marcha. A pesar de ello ha seguido andando solo por la calle, sin bastón. Y se ha casado, ha tenido hijos, ha ejercido su profesión... y se ha jubilado a la edad reglamentaria, lo que aprovecha ahora para acudir con asiduidad al gimnasio. Aunque nunca ha presentado brotes francos, sí que ha sufrido ciertas oscilaciones en la expresividad de su cuadro. Así, p. ej., a últimos de 1995, durante unas dos semanas, se incrementó su dificultad en el andar. Cuando se levanta de una silla suele proyectarse hacia delante con excesiva premura e intensidad - probable consecuencia de la discronometría cerebelosa, en la nomenclatura de André-Thomas. Pero tanto ésta como otras peculiaridades, que son ya tradicionales en él, las vive con buen ánimo y hasta con una cierta jocosidad, no "mórica".

No se le practicó una RNM hasta el 28 de diciembre de 1995 encontrándose pequeñas lesiones focales de desmielinización en ambos centros semiovales de predominio izquierdo.

Lo vimos por última vez el 3 de enern de 1996. 
Comentario. Trátase, pues, de un caso de EM que se inicia muy insidiosa pero claramente hacia los 19 años y que hemos podido seguir personalmente durante más de medio siglo. El síndrome clínico es suficientemente típico: ataxia - si bien moderada -, de neto predominio axial y en la marcha, nistagmus, diplopia inconstante, síndrome piramidal asimétrico - al menos, a temporadas -de predominio derecho. Aunque jamás ha tenido brotes netos, sí que su cuadro clínico ha manifestado ciertas oscilaciones y no sólo desde el punto de vista de su apreciación subjetiva, sino también en cuanto a los signos (recuérdese lo dicho sobre el signo de Babinski). No ha hecho nunca tratamiento con esteroides. Y notablemente ha experimentado una agravación bastante brusca, aunque no severa, luego de 53 años de evolución. La RNM, reciente, cuadra con el diagnóstico clínico. El predominio de la desmielinización del centro oval a izquierda puede relacionarse con el síndrome piramidal derecho.

Caso 2. Conocí a Leocadia, nacida en 1930, el año 1943, cuando y donde Quico comenzaba a tener dificultades para pasar un riachuelo saltando de una a otra piedra. No presentaba entonces, tenía 13 años, ningún distúrbio, de tipo neurológico.

Es el 17 de enero de 1958 , cuando tiene 28 años, que nos pide ayuda a mi padre y a mí porque hace un mes - dice - se inició una hemiparestesia derecha que comenzó, a la vez, por el dedo gordo del pie y hacia la zona de la muñeca, acompañandose de una sensación de que tiene menos dominio de la extremidad inferior derecha - de la rodilla expresa ella esquemáticamente - que de la izquierda. También refiere mareos al realizar algunos movimientos de la cabeza, aunque sin vértigo accesional franco, pero sí alguna vez con vómitos.

En la exploración anotamos una hipoalgesia hemilateral derecha, com disestesias en algunas zonas, p. ej., la periauricular. La sensibilidad vibratoria está abolida en el maleolo externo derecho y disminuída en el resto de esta pierna. La maniobra de Barré es ligeramente positiva a derecha. La marcha a ojos cerrados muestra una ligera desequilibración. La exploración sistemática pone de manifiesto una palidez bitemporal de las papilas ópticas. En frente de un sólo brote, pero con diseminación de lesiones en el SNC, se establece el diagnóstico, en la sistematización entonces al uso, de EM probable.

El cuadro remite y no vemos a la enferma en tanto que tal, si bien seguimos en contacto como amigos, hasta el 4 de julio de 1975. En tal fecha aqueja un mareo, poco específico, con sudoración fría y palidez, que la obliga a encamarse reiteradamente y también molestias en región interna y en el dedo gordo del lado derecho.

La exploración muestra una leve hiperreflexia del rotuliano - no del aquíleo - y de los braquiales, en el lado derecho, comparativamente al lado izquierdo. El reflejo cutáneo plantar es normal en ambos lados. La maniobra de Barré aparece como muy ligeramente positiva en sus tres tiempos en el lado derecho. La motilidad ocular extrínseca es normal, con tan sólo algún esbozo de sacudida nistagmica. Sigue - y seguirá - como ha constatado recientemente (1995) un oftalmólogo - la palidez bitemporal de papilas. La prueba dedo-nariz la realiza bien. Y la sensibilidad vibratoria se ha normalizado.

La mujer ha seguido una vida normal a lo largo de todos estos años, si bien en nuestras últimas conversaciones (enero de 1996) nos dice que se siente más fatigada cuando pasa largos ratos de pie (en la cocina, etc.) o andando, lo que tal vez pueda estar influído también por problemas artrósicos.

Ha tenido dificultades esfinterianos más o menos moderadas desde su segundo brote, discreto (el de 1975), habiendo debido consultar con el urólogo (Prof. I. Ponce de León).

Una RNM practicada el 27 de febrero de 1990 mostró "una lesión de características isquémicas o desmielinizantes a nivel de la region más pósteroinferior izquierda de los pedúnculos cerebrales, otra en el hemibulbo izquierdo y una tercera en el hemisferio cerebeloso izquierdo". Y además, una atrofia moderada del vermis cerebeloso y un moderado aumento de la profundidad de los surcos corticales cerebrales (tenía entonces 60 años). La neuroimagem confirma, pues, el diagnóstico de EM y, si cabe decirlo, ofrece una amplitud y diseminación de las lesiones que supera lo que una evolución tan benigna nos podería hacer presumir, lo cual, por lo demás, no es en modo alguno excepcional.

Aunque preocupa, en teoria al menos, la lesión hemibulbar, la enferma nos asegura (el 12.I.96) que no tiene otras dificultades cuando come que las que le procura a veces una hernia diafragmática que sufre. Nunca disfagia, ni tampoco modificaciones de la voz, la que es igual a cuando la conocí hace 53 años. 
Comentario. Para no reiterar lo que hemos expuesto al relatar su historia, nos limitaremos a resaltar el curso muy benigno de esta enferma, que lleva en la actualidad, cerca de sus 66 años, una vida prácticamente normal, con algunas molestias esfinterianas, etc. Ya queda comentada, por otra parte, la cuestión del relativo contraste entre la extensión de las lesiones en la RNM y la clínica.

Caso 3. Emilia, nacida en 1936, comenzó a presentar disturbios de funciones del SNC a los 28 años, en octubre de 1964. Como quiera que entre ellos sobresalían los transtomos del control vésico-uretral, un facultativo de Badalona la envió al Dr. I. Ponce de León, entonces en la Fundación Puigvert. Al constatar este urólogo que sus disturbios eran de origen neurológico nos la remitió de inmediato a la consulta externa del Servicio de Neurologia del Hospital de la Sta. Creu i St. Pau. La primera historia se extravió, pero 10 años más tarde (el 20.XII.1974) el Dr. J.M Grau Veciana redactó la siguiente:

Ya en 1956, a los 20 años, empezó a presentar sensación de acorchamiento de ambas extremidades inferiores, ascendiendo hasta el hipogastrio en pocos días. Al mismo tiempo comenz 6 a sufrir transtornos esfinterianos urinarios, con micción imperiosa, alternando con retención. Todos los sintomas desaparecieron al cabo de un mes. Pero pasado medio año volvió a presentar, durante unos tres meses, los mismos disturbios.

Unos 4-5 años más tarde empezó a presentar disminución de la agudeza visual en ojo derecho, que empeoró en pocos dias. Fue por ello que fue operada de sinusitis en otro hospital. Pero antes ya de ser intervenida, un mes después del inicio de la ambliopía, había empezado a mejorar, recuperando por completo la visión.

Hacía unos 5 años (15 después del inicio de su proceso) comenzó a apreciar falta de fuerza en extremidades inferiores, reapareciendo sus disturbios urinarios, siendo tratada con ACTH.

Dos años más tarde presentó nuevamente disminución de la visión en ojo derecho, llegando casi a la amaurosis, si bien al cabo de un mes, aproximadamente, se recuperó completamente.

Los síntomas de patología urinaria son los únicos que se han mantenido a lo largo de toda su afección, siendo tratada en los últimos tres años de infecciones urinarias recidivantes. El Dr. Vicente le practicó una intervención en el cuello vesical.

Sin que pueda precisar desde cuando, de forma inconstante y recurrente sufre sensaciones de inestabilidad.

Pasemos ya de la precisa historia levantada por el Dr. Grau a lo esencial de los datos de la exploración neurológica.

Los reflejos rotulianos, así como los aquilianos, estaban moderadamente exaltados y de forma asimétrica, más en el lado derecho. Los braquiales eran normales. Existía un signo de Babinski bilateral. La maniobra de Romberg ponía de manifesto vacilaciones de la equilibración. La marcha en tandem no era posible. No se constataron anomalías por parte de los pares craneales ni de las sensibilidades.

Un año más tarde comprobamos una exploración sensiblemente igual, con esbozo de reflejos de defensa (flexión dorsal refleja del pié, según el criterio estatuído por Babinski).

Desde entonces hemos mantenido estrecho contacto con Emilia, visitándola alrededor de 3040 ocasiones. Ha tenido de ser tratada asiduamente en la Fundación Puigvert por sus problemas de vías urinarias inferiores. Ha presentado siempre la típica "disociación" o disparidad signos/síntomas, siendo aquellos más expresivos que las limitaciones impuestas por estos últimos. Ha sufrido brotes reiterados, aunque bastante espaciados y nunca severos, habitualmente o siempre a expensas de sintomatología de extremidades inferiores: debilidad motriz, espasmodicidad, parestesias. En tales casos se trató con ACTH sintético retardado.

Se le practicó una RNM de cráneo - encéfalo - y médula espinal, el 17.XI.1986, la cual mostró lesiones hiperintensas de pequeño tamaño en ambas localizaciones.

Tuvo que ingresar en nuestra Sala, al cuidado de la Dra. Anna M. Barraquer Feu, del 26. VI al 3. VII de 1988, por un nuevo brote, que entorpecía su deambulacion, siendo tratada con metilprednisolona endovenosa. Luego de la mejoría que experiment 6 aquejaba fatigabilidad, la cual procuramos corregir con "amantadina". También ha tomado con frecuencia baclofen por su espasticidad y "ditropan", entre otros tratamientos, por sus problemas vésico-esfinterianos. 
Ya desde años atrás se excluyó una impresión basilar.

Ha ido aumentando la exaltación de los reflejos rotulianos y aquíleos y por parte de los pares craneales encontramos una primera anomalía - anotada por el Dr. R. Blesa el 14.IV.1980 - consistente en breves sacudidas nistágmicas, de tipo rotatorio-horario, agotables. También se tomó nota de que al mirar hacia arriba se desencadenaba un parpadeo sumamente brusco, digamos "clónico".

Ulteriormente se le practicó una nueva RNM, que tan sólo mostró discretas modificaciones respecto a la primera.

En el último contacto con la enferma (el 12 de enero de 1996) se confirma una vez más que sigue siendo capaz de llevar una vida normal, ocupándose de su hogar, etc., aunque con ciertas limitaciones.

Comentario. En este caso la evolución del proceso roza o abarca el compás de 40 años. Los brotes han sido mucho más reiterados que en las dos primeras observaciones, apareciendo algunos de ellos hace muy pocos años, a los 37-38 años de haberse iniciado el proceso, pero nunca han sido severos. Obviamente no es usual la presentación tan tardia de dichos brotes, lo que debe traducir una "fórmula auto-inmunitaria" de curso singular en el tiempo.

\section{CONCLUSION}

Tanto Quico como Leocadia y Emilia, afectos indudablemente de EM, han podido llevar una vida normal, atendiendo a sus familiares, dedicándose plenamente Quico a su profesión hasta su jubilación reglamentaria. El vive muy cerca de mí y nos cruzamos con frecuencia por la calle, charlando de nuestros viejos recuerdos. Mi esposa y yo cenamos con relativa frecuencia en casa de Leocadia y los suyos. Emilia y su esposo me han obsequiado reiteradamente por Navidad cuando mi onomástica y de forma harto consistente y emocionante cuando mi jubilación hospitalario administrativa el 27 de abril de 1993.

Clínicamente tales casos nos permiten de forma harto holgada resaltar la existencia de formas "muy benignas" de EM, lo cual, juzgamos por nuestra parte, que debe ser tenido más en cuenta, tanto por la clase médica como por los llamados "mass-media" en los momentos en que se establece o en que se comenta la evolución de este proceso morboso, tan diferente de unos pacientes a otros.

Obviamente, no se nos esconde que mediante el recurso a los fármacos ahora ya en ensayo y a otros ulteriores, el panorama al que nos referimos puede hacerse globalmente aún mucho más esperanzado.

Agradecimientos - Agradecemos a Quico, Leocadia y Emilia la libertad que nos han otorgado para difundir sus respectivas historias clínicas utilizando sus nombres de pila, como una prueba más de la amistad que nos une. 